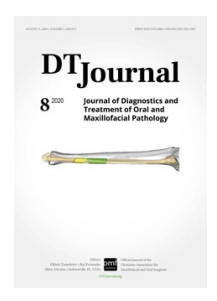

Post Scriptum Editorial

\section{Instagram Channel: Do We Use Its Full Potential?}

\author{
Oleksii 0. Tymofieievà, Natalia 0. Ushkob, \\ \& levgen I. Fesenkoc
}

If you've got an idea, start today.

-Kevin Systrom

Co-founder of the Instagram

Growth of the journal is undoubtedly based not only on hard scholar work of the editorial team but also on realization of ideas in social media (SM) and moving forward journal's own SM account (the term 'SM account' can be equated to team 'channel' as everyone can use its 24/7 uploading images/videos). Plastic and Reconstructive Surgery (PRS) shows us how the journal's development can be additionally accelerated using Instagram: 2019 Impact Factor (IF) of the journal became all-time high, reaching 4.209. ${ }^{1}$

Analysis of Instagram accounts of other publications show us next. As of August 25, the PRS account (@prsjournal) has 20,5 k followers; PRS Global Open (@prsglobalopen), the 8-year-old sister journal of $P R S$ with no IF yet, has 6048 followers, the account (@nejm) of New England Journal of Medicine (IF is 74.699) has $404 \mathrm{k}$ followers; the Obstetrics \& Gynecology (IF is 5.524) has 2735 followers in its account (@greenjrnl); the Orthopedics (IF is 1.409) has 2466 followers in its @ortho_journal account,

Kyiv, Ukraine

${ }^{a}$ Editor in Chief, dtjournal.org.

tymofeev@gmail.com

${ }^{\mathrm{b}}$ Editorial Board Member, dtjournal.org.

natalia.ushko@gmail.com

${ }^{\mathrm{c}}$ Managing Editor, dtjournal.org.

i.i.fesenko@dtjournal.org and our 4-year-old journal has 1631 followers in the account @dt_journal (Fig 1).

The publication experience of the editorial board (EB) shows that Instagram really works. ${ }^{2,3}$ It works in attracting authors/editors, widening audience of readers, more rapid formation of new journal's brand, etc.

So, the main question every EB should ask them is "How do we use the potential of the Instagram channel?" After all, the channel in a fastest growing SM with 1 billion global users. Whether we use the potential to the maximum, or just a little, or do not pay attention at all?

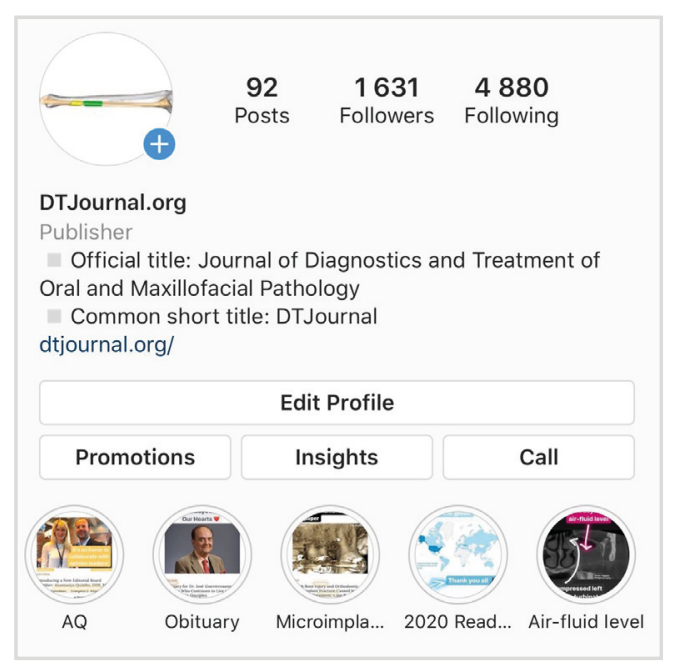

FIGURE 1. Instagram channel of the dtjournal.org.

\section{REFERENCES}

1. Plastic and Reconstructive Surgery [document on the internet]; August 25, 2020 [cited 2020 Aug 25]. Available from: https://journals.lww.com/ plasreconsurg/pages/default.aspx.

2. Tymofieiev OO. Swimming in the oceans of media technologies. J Diagn Treat Oral Maxillofac Pathol 2017;1(2):57-8.

3. Monteiro JL, Fesenko II. Every hashtag matters: an importance of that Instagram tool in a life of the peerreviewed journal. J Diagn Treat Oral Maxillofac Pathol 2019;3(5):A11.

\footnotetext{
Please cite article as: Tymofieiev OO, Ushko NO, Fesenko II. Instagram channel: do we use its full potential? J Diagn Treat Oral Maxillofac Pathol 2020;4(8):150.

Paper received 25 August 2020

Accepted 27 August 2020

Available online 31 August 2020

https://dx.doi.org/10.23999/j.dtomp.2020.8.3.

(C) 2020 OMF Publishing, LLC. This is an open access article under the CC BY license (http://creativecommons.org/licenses/by-nc/4.0/).
} 